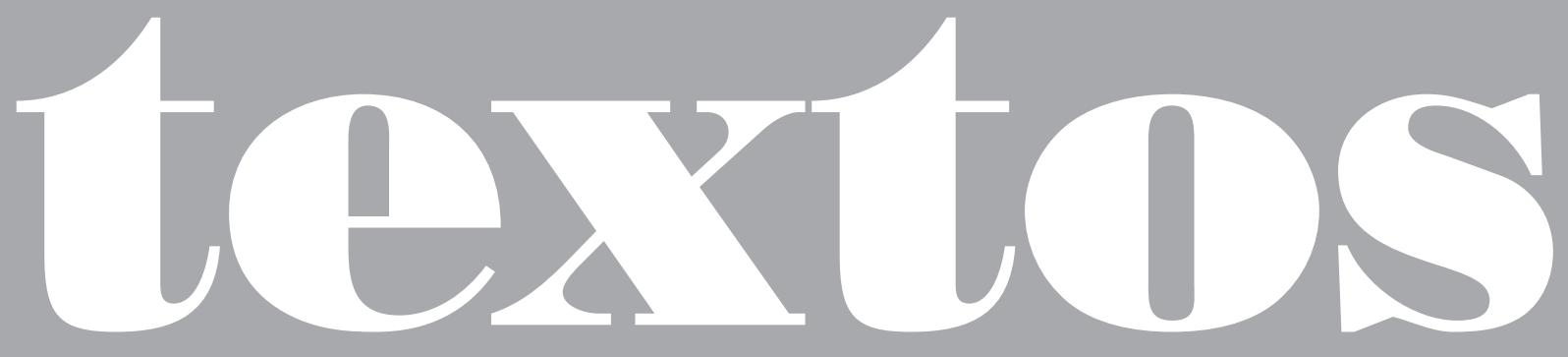





\title{
Auguste Herborth e o art déco guarani: diálogos França-Brasil (1920-1930)
}

\author{
Marisa Midori Deaecto
}

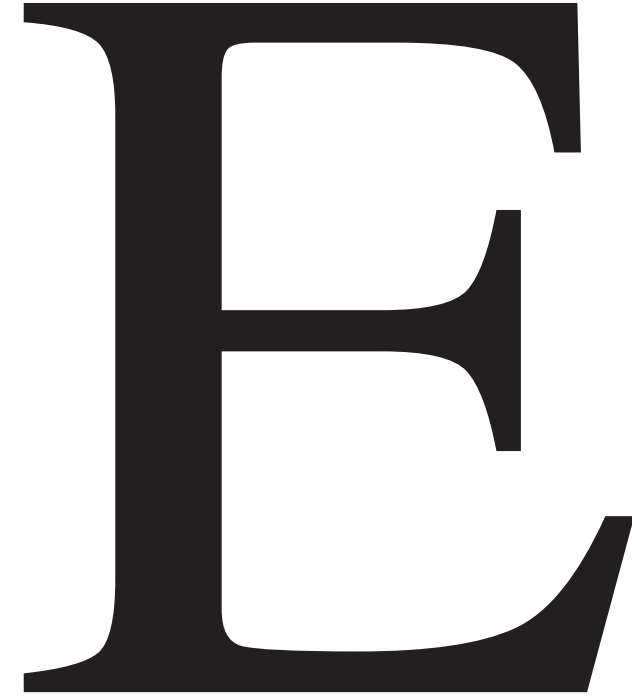

m 2014, a Bibliothèque Nationale et Universitaire de Strasbourg (França) celebrou a reinauguração do edifício central com uma série de atividades destinadas a reconstituir o passado, a repensar seu papel na atualidade e a propor novos projetos para o futuro.

Aos senhores Albert Poirot, diretor geral da BNU, Christophe Didier, diretor adjunto da BNU, e Frédéric Barbier, membro do Instituto de Estudos Avançados da Université de Strasbourg e curador do projeto histórico da BNU, os mais sinceros agradecimentos pelo convite para compor a equipe de pesquisa histórica da BNU e pela estadia agradável, além de muito laboriosa, em Strasbourg, em outubro de 2014.

MARISA MIDORI DEAECTO é professora do Departamento de Editoração da Escola de Comunicações e Artes (ECA) da Universidade de São Paulo. 


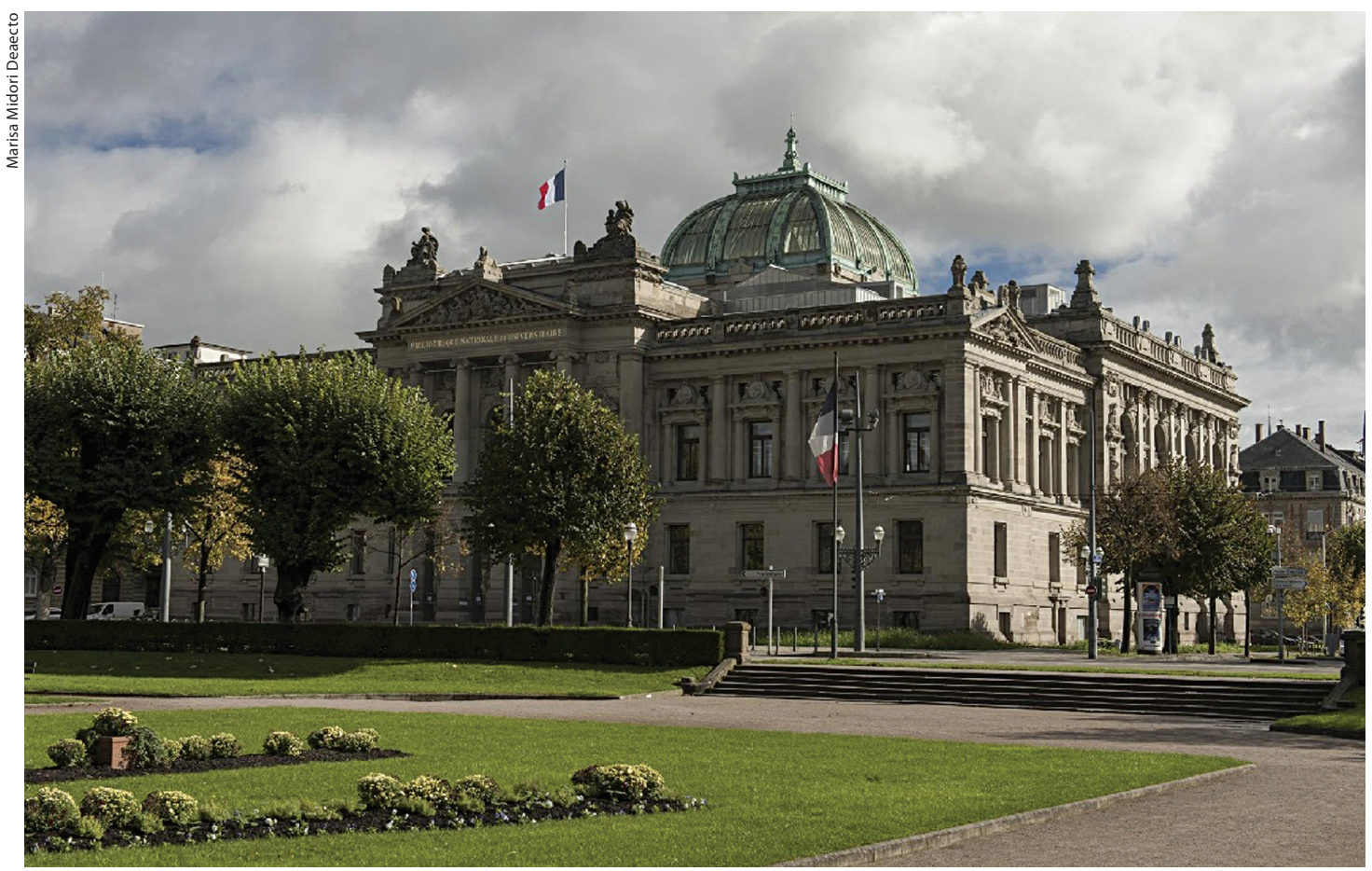

Fachada imponente da Bibliothèque Nationale de Strasbourg (BNU), na Place de la République, 2013

$\mathrm{O}$ antigo prédio, erguido dos escombros de uma cidade devastada pela ocupação alemã, em 1870, foi totalmente reformado. A fachada se manteve, imponente, tal como fora erguida na antiga Kaiserplatz, atual Place de la République, reforçando a importância simbólica de uma instituição marcada pelas guerras franco-alemãs, nas bordas do Reno. Mas o interior foi todo transformado e aparelhado com o que há de mais moderno em termos de equipamentos de segurança, acondicionamento de livros e de documentos, a criação de mesas de estudos e de salas ambientadas para a leitura individual e para as reuniões em grupo. Também foram atualizados os sistemas de empréstimos e devolução de livros, organizados os espaços de exposições... enfim, a nova BNU adaptou-se às mudanças dos tempos, sem, todavia, perder sua identidade ${ }^{1}$.
No que toca ao levantamento do acervo e à reconstituição de sua memória, alguns pesquisadores foram convidados a percorrer os desvãos dos antigos corredores recobertos por estantes, a remexer os papéis avulsos e a inquirir, entre pastas e objetos de vária sorte, sobre o passado daquela instituição. A presença brasileira estava lá, desde os primórdios da fase alemã, e se fortaleceu no entreguerras, após a retomada da administração francesa.

1 A relação de Strasbourg com os livros é muito forte e remonta à história profunda da cidade e de suas primeiras bibliotecas, na Alta Idade Média. Lembremos que, nos anos de 1440-50, Gutenberg iniciou ali sua carreira, de tal sorte que a cidade reivindica a primazia na história da imprensa, ao lado de Mainz, na outra margem do Reno. Mas foi nos tempos das duas ocupações alemãs, de 1870 a 1919, e durante a Segunda Guerra Mundial, que esse vínculo forte de Strasbourg com a nação se acentuou. Donde os títulos Kaiserliche Universitäts - und Landesbibliotek e, até nossos dias, Bibliothèque Nationale et Universitaire (BNU). Cf. Barbier (2015). 


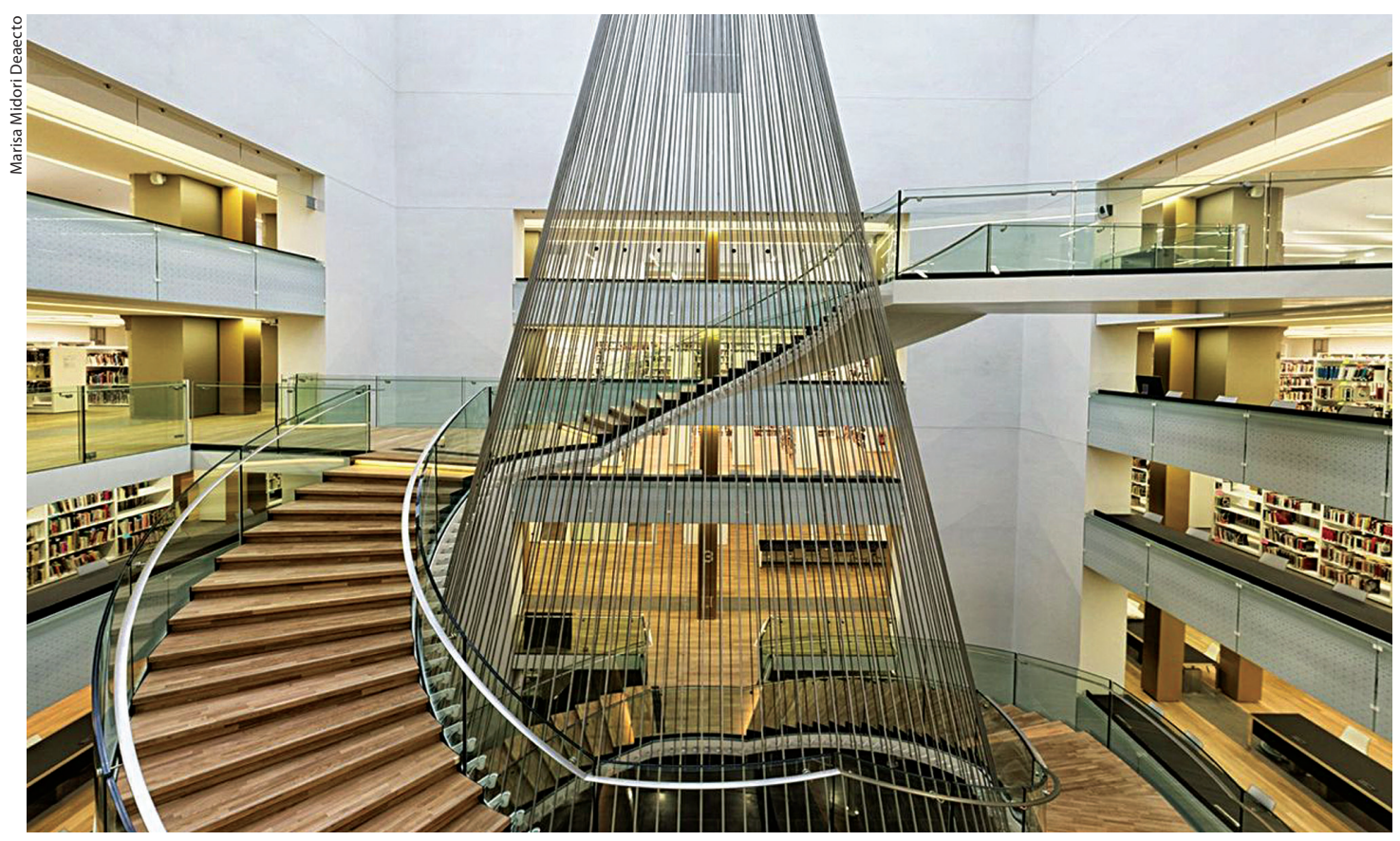

Hall de entrada, após as obra de modernização do interior, 2013

Vemo-la uma vez mais na década de $1970^{2}$. Não seria o tempo de reabilitá-la?

O primeiro conjunto de documentos que testemunha os diálogos entre a BNU e o Brasil se materializou no Fundo Gobineau. A origem desse fundo arquivístico remonta à anexação da Alsácia-Lorena pela Alemanha, pelo Tratado de Frankfurt, assinado em 10 de maio de 1871. Entre as novas aquisições promovidas pela instituição há livros, documentos e objetos de arte deixados pelo conde Arthur de Gobineau (1816-1882), um diplomata de origem francesa que estreitara, desde o início de sua

2 Não vamos nos deter sobre esse evento, pois, malgrado seu interesse, ele já se apresenta deslocado no tempo em relação às atividades desenvolvidas na década de 1930. Registramos, todavia, seu título: "Exposition Les Amériques - de la Découverte à I'Indépendance", de 18 de março a 30 de abril de 1977. O catálogo impresso das obras expostas na BNU me foi gentilmente cedido por esta instituição e merece, sem dúvida, um estudo à parte. carreira, laços com nobres e intelectuais alemães. Escritor prolífico, deixou uma obra polêmica, cujo título mais eloquente foi o Ensaio Sobre a Desigualdade da Raça Humana (Gobineau, 1853-1855), escrito que teria alimentado os projetos pangermanistas e, antes, as teorias raciais em voga no último quartel do oitocentismo (Deaecto, 2016). Em 1894, fora fundada a Gobineau-Verheinigung, sob a direção de Ludwig Schemann, de Freiburg-en-Brisgau. Em 1903, o fundo Gobineau seria vendido à $\mathrm{BNU}$, pelo valor de 20 mil marcos $(\mathrm{Ca}$ talogue, 1972, p. 40; Deaecto, 2015). Desde então, a coleção se enriqueceu com novas doações, entre móveis, pinturas, esculturas e correspondências várias, trocadas por Gobineau com seus amigos: Prokesch-Osten, Alexis de Tocqueville, Ernest Renan ${ }^{3}$,

3 De Ernest Renan, ele conservou as primeiras edições com dedicatórias. 
Richard Wagner, Madame de La Tour e... d. Pedro $\mathrm{II}^{4}$.

Os anos vividos pelo ministro plenipotenciário francês no Rio de Janeiro, entre março de 1869 e maio de 1870, significaram para o imperador brasileiro e o diplomata o início de uma longa e intensa amizade que se estendeu durante as viagens do imperador pela Europa e o Oriente, perpetuando-se em uma longa troca de missivas. As cartas do imperador brasileiro estão depositadas na BNU. Em 1932, todo esse material foi apresentado ao público em "Arthur de Gobineau - Exposition à l'occasion du cinquantième anniversaire de sa mort", cujo catálogo apresenta um primeiro balanço do fundo arquivístico que guarda seu nome (Bibliothèque Nationale et Universitaire de Strasbourg, 1933). O Brasil foi então representado pelo embaixador Luís Martins de Souza Dantas. Dois anos mais tarde, vamos reencontrá-lo novamente na BNU. Mas, agora, em um evento totalmente dedicado à arte brasileira. É o que veremos nos tópicos seguintes.

\section{QUANDO 0 BRASIL VIROU NOTÍCIA EM STRASBOURG}

Na noite de 28 de novembro de 1934, a BNU lançava ao público uma experiência artística inusitada. Auguste Herborth, um artista da terra, expunha, pela primeira vez para seus conterrâneos, os resultados de suas vivências e pesquisas realizadas no Brasil, nas áreas da cerâmica e do desenho aplicado

4 As cartas do conde de Gobineau endereçadas a d. Pedro II foram conservadas nos arquivos do Château D'Eu. Sobre as relações de Gobineau com o Brasil e a edição das cartas trocadas entre o conde e o imperador, cf. Readers (1938). a móveis e objetos decorativos. Tratava-se da "Exposition d'Art Guarany" ou, como se lia nos jornais, "uma curiosa e interessante exposição, cujo tema era desconhecido pela maior parte dos moradores de Strasbourg"5.

A elite intelectual strasbourgeoise compareceu em peso ao evento, sendo recebida por Wickersheimer, diretor da BNU. O artista e anfitrião Auguste Herborth pôde apenas ser reconhecido com certa dificuldade, o que nos dá bem a dimensão da afluência do público. Os jornais da região registraram algumas autoridades ali presentes:

"Lévy, Vice-Cônsul do Brasil (o patrono dessa manifestação artística foi Sua Excelência o Embaixador do Brasil, L. M. de Souza Dantas ${ }^{6}$ ); o general Pouydraguin, os senhores reitores Strohl e Forster; os senhores professores Lapparent, Bounours, Simon, Waitz, Kayser, Forrer, Reiss etc., além

5 Nouvelles de Strasbourg, 28/11/1934 [signé M. L.].

6 Luís Martins de Souza Dantas (1876-1954) foi diplomata de carreira, tendo iniciado sua gestão na Embaixada do Brasil em Paris, em 1922. Embora devesse se aposentar em 1941, aos 65 anos, sua carreira se prolongou em virtude da guerra e da dificuldade de substituí-lo. Após a invasão do escritório da Embaixada em Vichy, Souza Dantas ficou internado em Bad Godesberg, sendo efetivamente aposentado somente em dezembro de 1944, por um decreto-lei do presidente Vargas, aos 68 anos. Em 1946, representou o Brasil na I Assembleia Geral da ONU, reunida em Londres. Em seguida compôs a delegação brasileira na Conferência da Paz, chefiada pelo então ministro das Relações Exteriores, João Neves da Fontoura. Durante a longa estadia na França, tornou-se figura notada e notável no meio político e intelectual. É muito provável que tenha facilitado o trânsito de professores e de artistas entre o Brasil e a França, o que explicaria seu nome e sua presença como patrono da exposição de arte guarani, ou até mesmo a estadia de Henri Tronchon, professor da Faculdade de Letras da Universidade de Strasbourg, no Rio de Janeiro, onde, segundo Antonio Candido, ele teria introduzido os estudos literários comparados. Sobre a carreira do diplomata Luís Martins de Souza Dantas e sua atividade em auxílio aos judeus, durante a ocupação nazista na França, cf. Franco (2008, p. 19) e Koifman (2002). 
de numerosos artistas: Blumer, Braunagel, Beecke, Graeser, Haffen etc., nomes citados ao acaso, a título puramente indicativo, entre tantas outras personalidades perdidas na multidão"7.

Difícil não se render à crônica da sociedade strasbourgeoise, sobretudo quando ela focaliza de modo tão expressivo os quadros de sua prestigiosa universidade e de seus artistas, em uma só palavra, sua intelligentzia. Deve-se mesmo perguntar em que medida a cité, tão bem representada nos jornais da região, mantinha relações com a população da cidade como um todo. Noutros termos, será que a exposição consagrada à arte guarani fez eco entre os locais? Ela foi bem recebida pelo público, tanto quanto o seria pela crítica?

A exposição ficou em cartaz de 29 de novembro a 20 de dezembro de 1934. Era aberta todos os dias, das 14 às 16 horas, com entrada gratuita aos domingos. Entre os papéis avulsos depositados nos arquivos da BNU, algumas anotações manuscritas dão conta da afluência do público. Registraram-se 291 visitantes, entre 68 pagantes e 223 gratuitos, no período de 28 de novembro a 10 de dezembro. Os números sugerem que as maiores visitas se deram aos domingos, quando a entrada era franca ${ }^{8}$.

É verdade que a crítica recebeu com certa reserva alguns aspectos da exposição. $\mathrm{O}$ entusiasmo maior dos jornalistas ficou por conta da explanação histórica sobre as cousas e gentes da América e do Brasil, de modo especial. A grande noite foi enfeixada pelo

7 Nouvelles de Strasbourg, 28/11/1934.

8 Cf. Dossier Exposition d'Art Guarany, Ms, BNU. discurso do professor Greiner, da Faculdade de Letras, que fez as honras da Universidade, sempre com a mesma "eloquência e erudição que lhe são reconhecidas" 9 . E o discurso deve ter sido relativamente longo, pois alimentou os jornais da região com histórias várias, não raro pitorescas sobre capítulos da época das descobertas. Dentre os fatos narrados, um jornalista recorda que

"a uma certa época, os guaranis foram os aliados dos franceses contra os portugueses; suas flotilhas atacaram com certa frequência os navios portugueses. O 'grande e poderoso rei Quoniambek’ (Cunhambebe), cujo retrato foi publicado por André Thévet em sua Vida dos Homens Ilustres, e sobre quem falou Hans Stade $[s i c]^{10}$, era um verdadeiro chefe, inimigo implacável dos portugueses [...] Após o advento dos brancos, eles foram civilizados - em detrimento de suas vontades, cumpre ressaltar - e sua língua foi horrivelmente alterada" ${ }^{11}$.

O autor faz referência à interessante obra de André Thévet, Les Vrais Povrtraits et Vies des Hommes Illvstres Grecs, Latins, et Payens Recueilliz de Leur Tableaux, Livres, Medalles Antiques, et Modernes... (Paris, Keruert et Guillaume Chaudière, 1584). Trata-se de um álbum (35 x 24 cm) ricamente ilustrado, com 221 gravuras em talho-doce, representativas dos biografados. A técnica é apresentada como uma novidade para a época, como bem assinala o autor

9 "Exposition d'Art Guarany à la Bibliothèque Nationale", in Journal de l'Alsace-Lorraine, 29 novembre 1934.

10 Staden (1557) apud Moraes (2010, t. 2, p. 371).

11 France de L'Est, 12/12/1934. 
no prefácio, o que demonstra seu cuidado com a edição. Sobre as personalidades pagãs (payens) trazidas do Novo Mundo, que figuram em sua galeria:

“As 'biografias' acompanhadas dos 'retratos' de 'Paracoussy Savriune, roy de Floride'; 'Paracoussy, roy de Platte [Rio de la Plata]'; 'Nacolabsou, roy du Promontoire des Cannibales' [localidade indeterminada, provavelmente Cabo da Boa Esperança]; 'Montezuma-Atabaliba'; e, por fim, de 'Cunhambêbê', o famoso índio aliado dos franceses no Rio de Janeiro e em São Vicente. Thévet chama-o de 'Quoniambec' e reproduz uma magnífica gravura do índio que afirma ter desenhado enquanto estava no Rio. Relata também os feitos do índio: 'cet effroyable Quoniambec, duque lie puis parler, pour l'avoir veu, ouy \& l'oisir remarqué à la riviere de Ianaire, où le Seigneur de Ville-gaignon nous avoit fait arrester" (Moraes, 2010, t. 2, p. 403).

A passagem resgata um capítulo importante da história das descobertas, a saber, a presença de missionários religiosos - católicos e protestantes - na costa brasileira e, também, de corsários, todos vindos do reino de França. Sabemos que os protagonistas na partilha do Novo Mundo foram a Espanha e Portugal, de tal sorte que ingleses e franceses tiveram uma presença marginal nesse primeiro momento. Porém, no que toca ao caso francês, essas viagens produziram toda uma literatura que registrou a presença de índios, de seus traços, de seus hábitos, num só termo, de sua cultura na América e na Europa. Afonso Arinos de Mello Franco faz um repertório exaustivo de toda essa produção, desde a presença célebre de mais de 20 indígenas que compuseram o décor da festa de entrada do rei Henrique II, em Rouen, em 1550 - cujos registros foram gravados em xilogravura, em bela edição publicada no mesmo ano $^{12}$ - até as notas de Montaigne sobre uma entrevista que o célebre ensaísta teria realizado, em 1562, com dois jovens índios levados por Nicolas Durand de Villegaignon para a França. A exemplo do que ocorreu com outros nativos da América, esses jovens foram batizados e viveram entre os franceses (Franco, 1937).

Para além das imagens expostas, o leitor era então convidado a conhecer (ou rememorar) todo um repertório bibliográfico responsável pela difusão de notícias da América veiculadas na Europa, ao longo do século XVI. Uma literatura, enfim, que gerou a produção de todo o imaginário sobre a natureza, os animais e os homens nativos daquelas terras incógnitas, a qual teria alimentado um mercado de impressos em pleno desenvolvimento e gêneros narrativos novos, que oscilavam entre a descrição pura dos fatos, com pretensões científicas, ou narrativas assumidamente fantasiosas. No final das contas, a exposição parecia despertar a sensibilidade do público para questões sempre vivas sobre os efeitos dos encontros e desencontros de mundos tão diversos, como aqueles provocados pelas

12 Lors de l'Entrée d'Henri ll à Rouen le $1^{\text {er }}$ octobre 1550, où figurent des Brisilians (sic) dans les Scènes Proposées aux Spectateurs. Collection de la Bibliothèque Mazarine - Paris (Rés. 17741, Cat. 65). Ana Maria de Moraes Belluzzo assinala uma versão manuscrita, ricamente ilustrada, pertencente ao acervo da Bibliothèque Municipale de Rouen. A bibliografia que versa sobre o imaginário europeu sobre o Novo Mundo é bem extensa. Um estudo específico sobre a festa de Rouen foi publicado à guisa de introdução do fac-símile de 1550 por Ferdinand Denis (1850). Outras referências figuram no clássico de Sérgio Buarque de Holanda (1959). Uma síntese de toda essa produção foi publicada por Ana Maria de Moraes Belluzzo (1995). 
grandes descobertas, no turbilhão de referências que caracterizou a Renascença ${ }^{13}$.

No intuito de chamar a atenção do público quanto às semelhanças dos traços guaranis com as linhas geométricas características de alguns artefatos europeus, Auguste Herborth emprestara do museu regional da Alsácia peças originais que foram justapostas aos desenhos ameríndios. Como se lê em um jornal: "Não é, com efeito, surpreendente, o fato de encontrarmos os mesmos motivos decorativos em objetos pré-históricos descobertos na Alsácia, os quais remontam ao ano 4000 e a 1500 antes de nossa era?"14. A questão se desdobra em referências conceituais mais profundas: "Trata-se de uma arte derivada do totemismo e do animalismo, ou seja, uma das artes primitivas cujo sentido foi revelado pela dita doutrina Kulturkreislehre (doctrina dei cicli culturali), ou doutrina dos círculos culturais"15. Essa ideia será retomada pelo jornal Neuste Nachrichten, embora as razões das coincidências surpreendentes observadas em manifestações artísticas tão distantes no tempo e no espaço continuem sem resposta ${ }^{16}$.

13 O repertório de viagem não escapa à percepção de Rabelais, que Ihe dá voz em seu Pantagruel (livre IV): "Là je veiz, selon mon advis, Hérodote, Pline, Solin, Beroze, Philostrate, Mela, Strabo et tant d'aultres anticques, plus Albert le Jacobin grand, Pierre Testemoing, Pape Pye Second, Paulle Jovio le vaillant homme, Cadacuist [Cadamosto], Tevault [André Thévet], Jacques Cartier [voyageur qui arrive au Canada en 1534], Haïton Arménien, Marc Paule Vénétien [navigateur qui part à l'Orient, jusqu'à l'Empire Chinois], Ludovic Romain, Pietre Alvarès [Pedro Álvares Cabral] et ne sçay combien d'aultres historiens cachés derrière une pièce de tapisserye, en tapinois escripvant de belles besognes, et tout pour Ouy-Dire" (Rabelais, 1997).

14 Nouvelles de Strasbourg, 28/11/1934.

15 France de L'Est, 12/12/1934.

16 Neuste Nachrichten, 29/11/1934.
Outras questões pareceram muito mais ambientadas nos conhecimentos adquiridos por etnólogos e arqueólogos atuantes na bacia amazônica desde finais do século XIX. O Journal de l'Alsace-Lorraine publicou uma descrição meticulosa dos objetos expostos, entre desenhos coloridos e em preto e branco, representações da arte rupestre descoberta na bacia amazônica, esculturas figurativas, onde se veem máscaras humanas ou de animais e alguns motivos decorativos que remetiam às lendas dos guaranis, aos seus modos de vida, à sua arte e às suas crenças. $\mathrm{O}$ crítico apenas lamentou, não sem justeza, a ausência de peças autênticas trazidas do Brasil. Uma exposição realizada "sem nenhum documento original”, como justificá-la ${ }^{17}$ ?

\section{A ALMA DO ARTISTA ENTRE DOIS MUNDOS}

Na década de 1930, Auguste Herborth era uma personalidade relativamente conhecida no meio strasbourgeois. Nascera em Strasbourg, em 1878, onde fez os estudos e se tornou professor, na École Municipale des Arts Décoratives. De 1906 a 1920 (Mehlstäubler, 2009, p. 83), trabalhou de modo infatigável no aprimoramento de sua técnica e de sua arte, o que lhe rendeu um lugar de prestígio entre outros artistas da região, a exemplo de Léon Elchinger e o grupo de ceramistas atuantes na outra margem do Reno, na cidade germânica de Elsas (Mehlstäubler, 2009, p. 83). A viragem na vida profissional se deu justamente nessa época, ao aceitar o convite para dirigir uma fábrica de porcelana no Rio

17 Journal de l'Alsace-Lorraine, 29/11/1934. 
de Janeiro ${ }^{18}$. Foi quando passou a dividir as horas de trabalho com os estudos realizados no Museu Nacional, tomando contato com expressões indígenas, em particular, com a cerâmica da Ilha de Marajó (Machado, 1937).

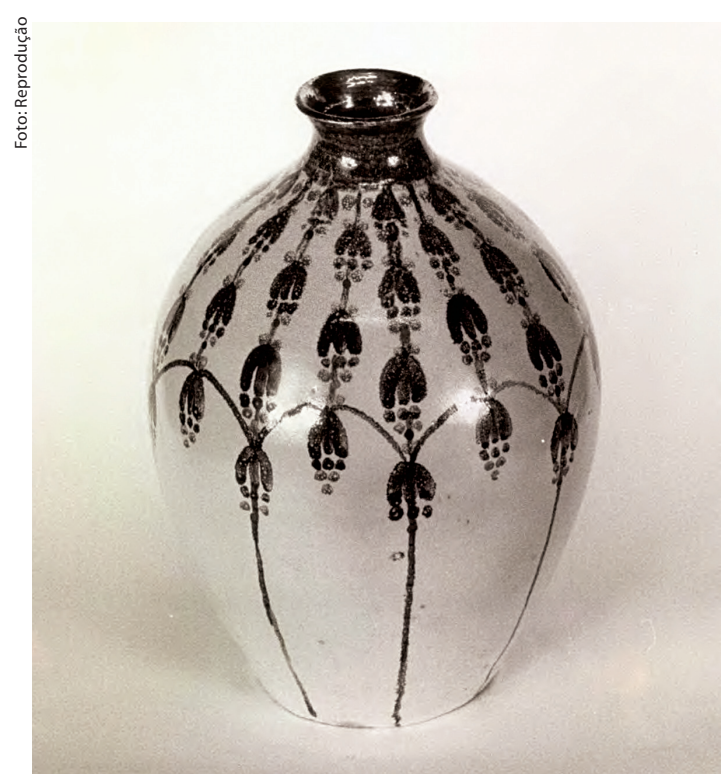

Vaso de cerâmica datado dos anos de 1920, de autoria de Auguste Herborth. Museu de Haguenau, Alemanha

Lembremos que a arte marajoara gozava de notável prestígio entre os artefatos colecionados no museu. As primeiras missões arqueológicas através do Amazonas datam de 1867, sob a direção de Ladislau Netto, arqueólogo do Museu Nacional do Rio de Janeiro. Mais tarde, nos anos de 1880, Orville Derby e Ferreira Penna se juntaram às missões na Ilha de Marajó.

18 Infelizmente, não podemos asseverar com precisão sobre o nome da fábrica, mas sugerimos se tratar da Companhia Cerâmica Brasileira, onde outro artista, Correia Dias, "desenvolve uma extensiva gama de artefatos destinados às casas brasileiras, em vasos, azulejos, pratos". Tudo isso, seguindo os "zigue-zagues, as gregas e tramas geométricas derivadas dos desenhos marajoaras" (Roiter, 2010, pp. 19 e 25).
Antes, em 1870, Charles Frederick Harrt, geólogo canadense, acompanhara Louis Agassiz em sua expedição pelo Amazonas. Em seguida, ele se instalou no Rio de Janeiro e dirigiu a primeira Comissão Geológica do Império (1875-1877). O autor de Notes on the Manufacture of Pottery Among Savage Races (1873), além de outros trabalhos que certamente interessaram ao artista strasbourgeois, assumiu a direção do Museu Nacional em 1876. Algumas anotações de leitura feitas por Herborth, durante as pesquisas preparatórias para a exposição na BNU de Strasbourg, confirmam seus conhecimentos da produção bibliográfica oriunda dessas expedições na bacia amazônica ${ }^{19}$. Os resultados desses anos de leituras e de pesquisas foram por ele compilados no volume Estudos Guarany (1921-1925), os quais constituem a matéria principal da exposição que o artista inaugurava em Strasbourg, passados três anos de seu retorno à terra natal ${ }^{20}$.

Embora tudo se apresentasse como uma grande novidade para a imprensa renana, Auguste Herborth bem conhecia a extensão dos movimentos artísticos que elegeram a arte indígena como a expressão mais genuí-

19 É o que vemos, por exemplo, em "Dessins sur roches du Brésil", in Dossier Exposition d'Art Guarany, Ms, BNU.

20 É o que apreendemos do seguinte documento: "Por carta de 4 de junho de 1935, o senhor me fez conhecer que Auguste Herborth desejava expor, nas dependências da Bibliothèque Nationale et Universitaire de Strasbourg, seus trabalhos (desenhos e aquarelas) relativos à arte guarani. Eu tenho a honra de vos comunicar que de minha parte não há nenhum inconveniente quanto ao que foi acordado entre você e o Sr. Herborth, no que toca à autorização que ele solicita, sob a reserva, entretanto, que esta exposição não gere nenhum gasto suplementar para a Biblioteca". Carta do conselheiro geral do Estado, diretor geral dos Serviços da Alsácia e da Lorena, ao administrador da Bibliothèque Nationale et Universitaire de Strasbourg, in Dossier Exposition d'Art Guarany, dactylo, BNU. 


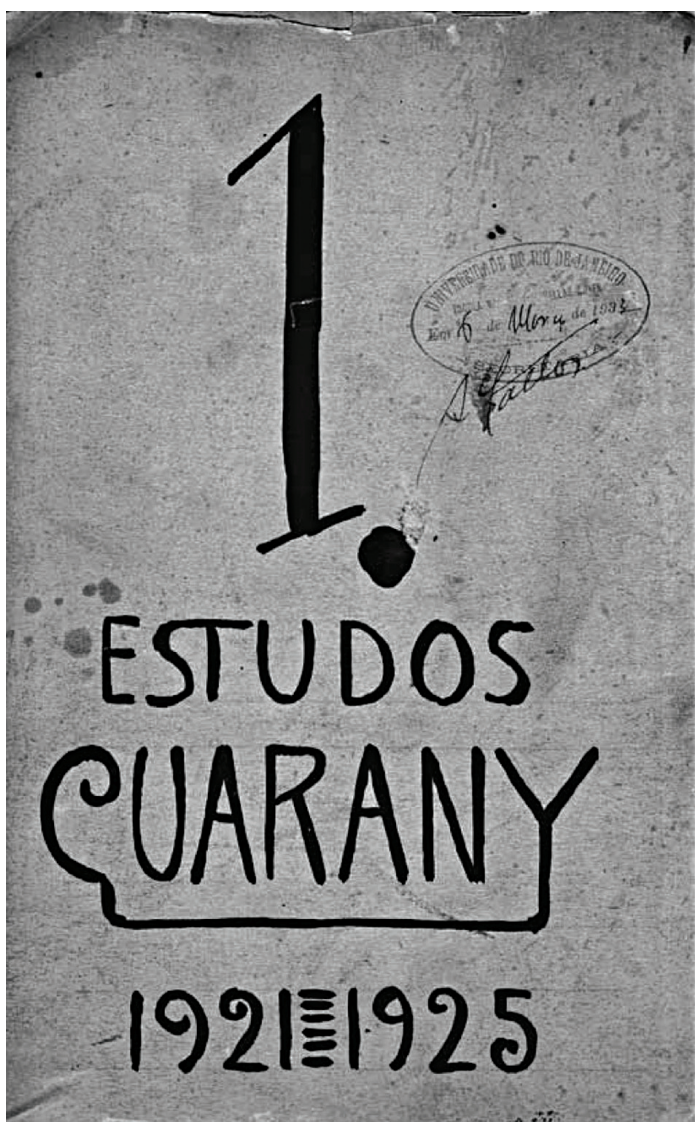

Frontispício de Estudos Guarany (1921-1925), de Auguste Herborth (Coleção Berardo, Lisboa). Fonte: Roiter, 2010, p. 27

na da brasilidade. Sabemos que ela estava no coração de alguns programas da vanguarda brasileira e que duas obras, em particular, guiaram a retomada das matrizes indígenas de nossa cultura: o Manifesto Pau-Brasil (1924), de Oswald de Andrade, constitui uma defesa da poesia nacional, pura, primitiva, sem os vícios da cultura acadêmica; em Macunaíma (1928), Mário de Andrade montou sua narrativa com base nas lendas indígenas do Amazonas. Mais precisamente, o autor recolhe as histórias do herói mítico Makunaima, as quais, por sua vez, foram compiladas pelo etnólogo alemão Theodor Koch-Grünberg, para o segundo volume de seu Vom Roraima zum Orinoco, de 1915 (Ramos Jr., 2012, pp. 20-1). Esses títulos testemunham as transferências de conhecimentos tomadas por uma ciência etnográfica e arqueológica em pleno desenvolvimento, o que diz muito do interesse do Velho Mundo pelas civilizações americanas e da capacidade criadora dos artistas do Novo Mundo. Vemos, aliás, que as referências circulam através do Atlântico e se convertem, aqui e lá, em programas, projetos e manifestações que tocam a literatura, mas também as belas-artes e as artes aplicadas ${ }^{21}$.

Em 1926, Auguste Herborth participou do Salão da Escola de Belas-Artes do Rio Janeiro, onde expôs, na seção de Artes Aplicadas, "três quadros de composição decorativa, entre os quais um alfabeto, um vocabulário, alguns desenhos e suas aplicações, todos inspirados na decoração dos indígenas brasileiros do baixo Amazonas". Ele recebeu o prêmio Pequena Medalha de Ouro por uma das peças expostas. É possível ver essas aplicações nos livros modernistas, em cujos exemplares saltam, com eloquência, a força dos motivos indígenas não raro integrados aos programas do art nouveau e do art déco. O desenhista $\mathrm{e}$ ilustrador de origem portuguesa, mas logo abraçado por artistas brasileiros, Fernando Correia Dias de Araújo criou exemplares que traziam essas matrizes indígenas, os quais constituem exemplos verdadeiramente notáveis no meio editorial brasileiro (Melo \& Ramos, 2011).

Enquanto isso, em Paris, Vicente do Rego Monteiro publicava Légendes, Croyan-

21 Disponível em: http://www.dezenovevinte.net/egba/ index.php. 


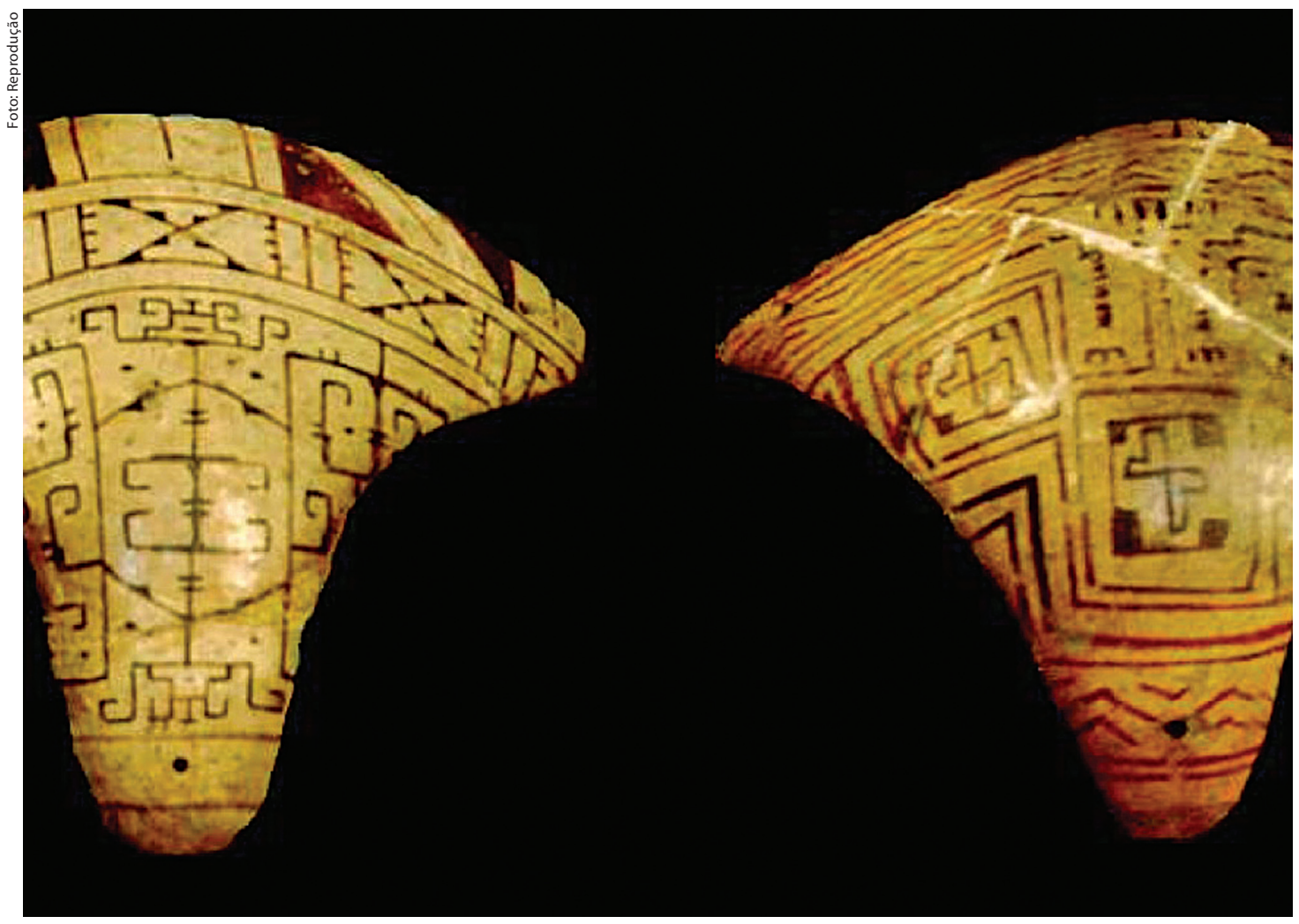

A tanga em duas versões: peça em cerâmica conservada no Museu Goeldi, em Belém do Pará (BRE), e, à direita, desenho estilizado de Vicente do Rego Monteiro. Fontes: Catálogo do Museu Goeldi; Monteiro, 1923

ces et Talismans des Indiens de l'Amazone (1923), volume raro, de tiragem restrita (500 exemplares), cujo roteiro se volta para aspectos da teogonia indígena. De um lado, "o poema noturno selvagem", de outro, "a causa de tudo, o princípio gerador, a Mãe, que se nomeia Ci” (Monteiro, 1923) ${ }^{22}$, surgem como um grande ballet. O texto é uma adaptação de P. L. Ducharte, tirada das narrativas transmitidas de acordo com a

22 Tomamos como fonte a edição fac-similar do exemplar de Ruy Sousa e Silva, traduzido por Regina Salgado Campos (Schwartz, 2005).

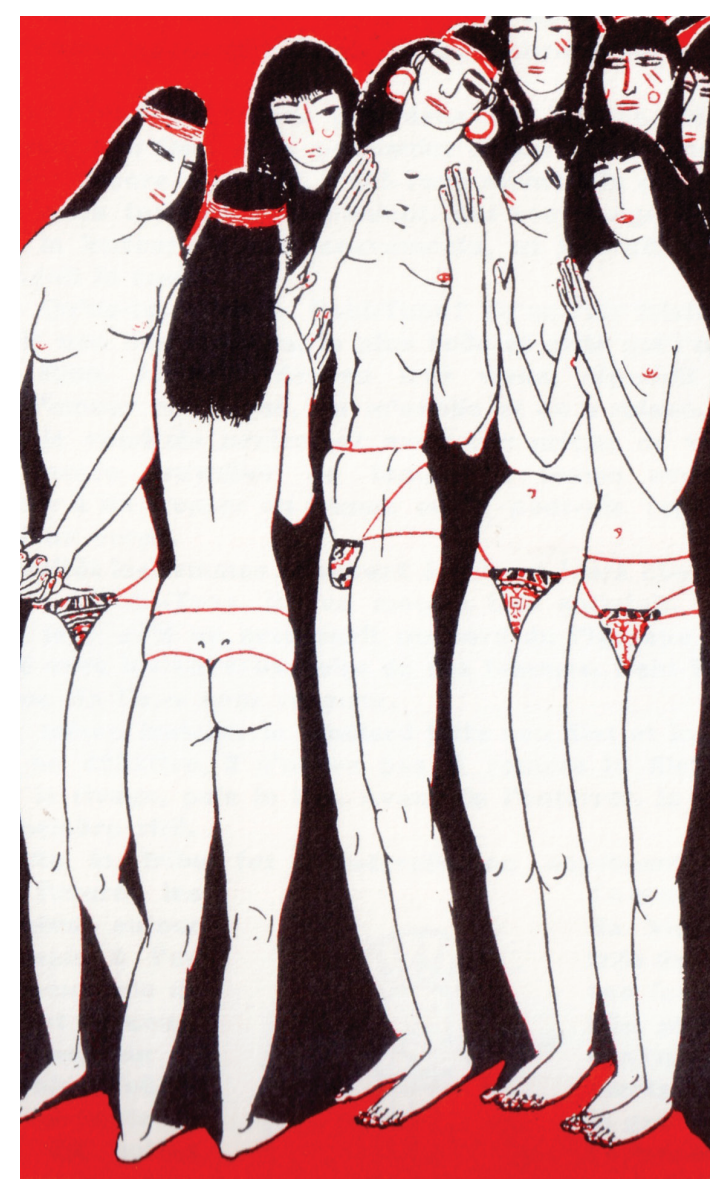


tradição oral desses povos. Rego Monteiro assina as ilustrações. Nelas, o artista brasileiro recria os motivos das cerâmicas expostas no Museu Nacional do Rio de Janeiro. Aqueles mesmos traços que alimentaram a imaginação do artista strasbourgeois.

Dois anos mais tarde, Rego Monteiro retomará os mesmos elementos, mas, dessa vez, há uma inversão bem significativa. É o que conta o autor no início do livro:

"Um dia, um chefe selvagem deixando a floresta virgem vem a Paris incógnito, ao final de uma breve estadia, ele retorna com ar blasé, tomado de tantas grandezas, à sua oca (home)... Ele então me confiou suas impressões de Paris, ao mesmo tempo que alguns croquis realizados nos locais, os quais eu reuni sob o título Algumas Imagens de Paris" (Monteiro, 1925) ${ }^{23}$.

Diferente das travessias realizadas no século XVI, por meio das quais os indígenas eram batizados, aculturados, num só termo, preparados para a vida civilizada (leia-se, europeia), agora o cacique fala por si mesmo, chegando a transferir elementos de sua teogonia aos objetos descritos. De um ponto de vista totalmente original, é o índio quem aplica seus traços geométricos nesta espécie de "caderno de viagem", no qual os monumentos da Cidade Luz são convertidos em... arte guarani!

Ao fim dessa longa viagem, parece justo questionar sobre o sentido da arte que se anunciava na distante Strasbourg dos anos de 1930. Pode-se supor que às expertises

23 Tomamos como fonte a edição fac-similar do exemplar de Ruy Sousa e Silva, traduzido por Regina Salgado Campos (Schwartz, 2005).

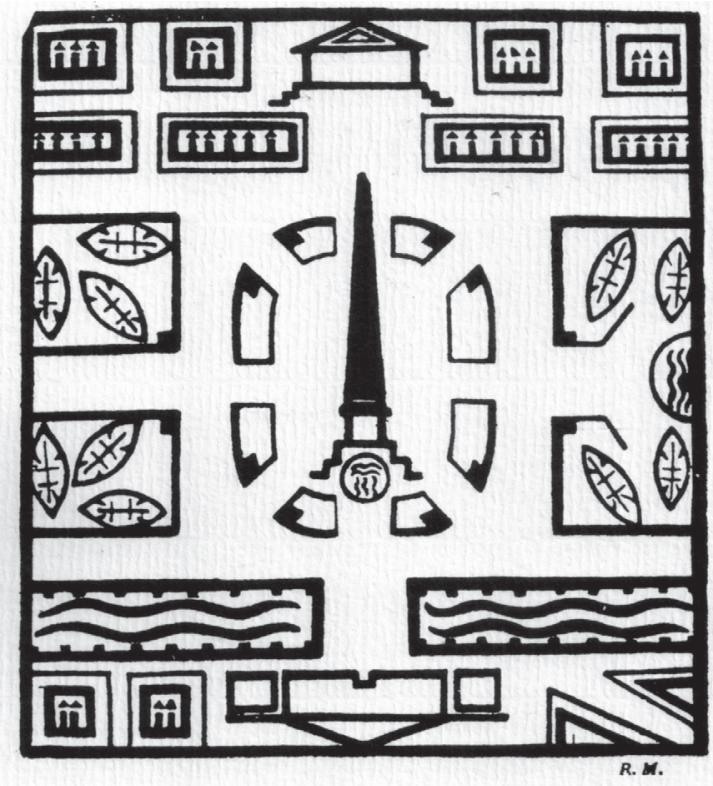

La Concorde, de acordo com um cacique. Fonte: Monteiro, 1925

já bem consolidadas na arte da cerâmica, Auguste Herborth soma os estudos sobre as aplicações dos motivos indígenas em um novo conceito de arquitetura e de decoração. Seguindo o movimento Art Déco, que atinge sua plenitude na feérica Paris dos anos de 1920, nosso artista se coloca em linha com as manifestações tropicais que conheceremos mais tarde sob a etiqueta de art déco Marajoara. Notemos que esta tendência ancorou tanto na França quanto no Brasil. É o que se observa, por exemplo, nas peças icônicas do ceramista Elisée Visconti ou ainda na nova arquitetura que se insinua em vários pontos das cidades do Rio de Janeiro e de São Paulo, entre 1920 e $1940^{24}$.

A novidade aporta em Strasbourg não sem a desconfiança de um crítico de arte

24 Márcio Alves Roiter (2010) apresenta uma série de exemplos dessa tendência, ao olhar de muito perto alguns edifícios cariocas, com suas ambiências icônicas. 
da região, como podemos observar nesta passagem:

"Quanto às aplicações possíveis da arte guarani e a fonte de inspiração nova que se observa para a arte decorativa moderna, na Europa, nós nos resguardamos profundamente céticos sobre as chances de sucesso de uma tal tentativa. As ideias que sugere Herborth, particularmente no domínio da decoração de interiores e de mobiliário, apenas confirmam nossa opinião sobre esse ponto" ${ }^{25}$.

Auguste Herborth faleceu em 1968, praticamente desconhecido pela crítica e pelo público. Desse capítulo brasileiro, de cujos trabalhos resultaram desenhos de toda sorte, "cerca de 500 pranchas em aquarela, guache e nanquim, explorando a temática marajoara em todas as áreas da arquitetura, decoração interior e design" (Roiter, 2010, p. 25) $)^{26}$, conhecemos apenas o exemplar pertencente à Coleção Berardo, de Lisboa. Interessa, enfim, registrar que nosso artista logrou reunir a mais importante coleção de motivos art déco em sua variante indígena brasileira ${ }^{27}$.

25 Journal de l'Alsace-Lorraine, 29/11/1934.

26 Entre os estudos históricos que levantam discussões e referências bibliográficas mais recentes sobre as releituras da cultura marajoara em sua vertente decorativa, citamos a pesquisa de Paola da Silva Pascoal (2012).

27 À senhora Carina Bento, do Museu Coleção Berardo, de Lisboa, nossos agradecimentos pelas preciosas informações sobre a fortuna artística de Auguste Herborth.

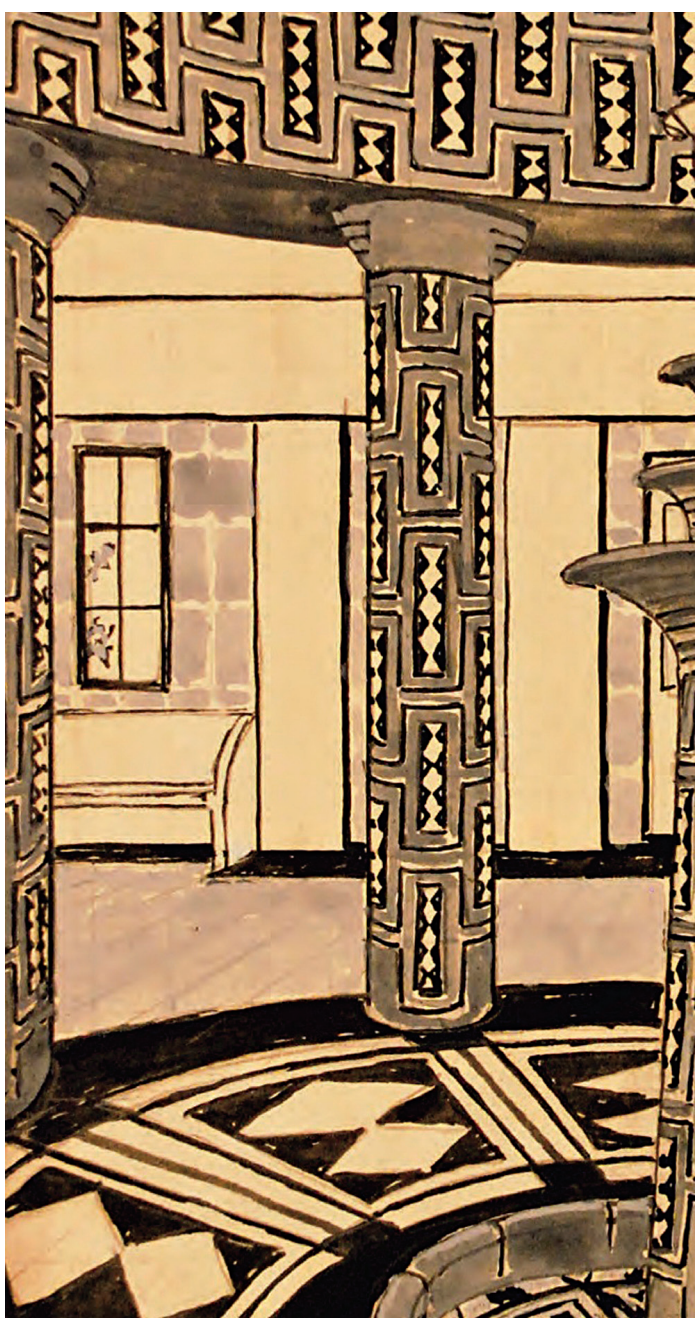

Decoração de interior, por Auguste Herborth. Fonte: Catálogo da exposição "Nouveau Art Déco, Estilos de Sedução”, 2013 


\section{BIBLIOGRAFIA}

BARBIER Frédéric (dir.). Bibliothèques. Strasbourg. Origines-XXIe siècle. Paris/Strasbourg, Éditions des Cendres/BNU, 2015.

BELLUZZO Ana Maria de Moraes. The Voyager's Brazil. São Paulo, Metalivros/Odebrecht, 1995, 3 v.

BIBLIOTHĖQUE NATIONALE ET UNIVERSITAIRE DE STRASBOURG, Exposition à l'occasion du cinquantième anniversaire de la mort d'Arthur de Gobineau (10-30 novembre 1932). Paris/Strasbourg, Les Belles Lettres/BNU, 1933.

CATALOGUE. Exposition Bibliothèque Nationale et Universitaire de Strasbourg - Cent ans d'acquisitions. Strasbourg, 4 décembre 1971-15 janvier 1972.

DEAECTO Marisa Midori. "Arthur de Gobineau e o Interregno Brasileiro (Março de 1869-Maio de 1870)", in Mouro - Revista Marxista. Núcleo de Estudos d'O Capital, ano 7, n. 10. São Paulo, janeiro de 2016, pp. 107-24.

"Le fonds Gobineau à Strasbourg: parcours d'une vie et de ses réalités historiques", in Bibliothèque Strasbourg - Origines-XXIe siècle. Sous la direction de Frédéric Barbier. Paris/Strasbourg, Éditions des Cendres/BNU, 2015, pp. 379-82.

DENIS, Ferdinand. Une Fête Brésilienne Célébrée à Rouen en 1550. Suivie d'un Fragment du XVle Siècle sur la Théogonie des Anciens Peuples du Brésil et des Poésies en Langue Tupi de Christovam Valente. Paris, J. Techener, 1850.

FRANCO, Afonso Arinos de Mello. O Índio Brasileiro e a Revolução Francesa. Rio de Janeiro, José Olympio, 1937.

FRANCO, Álvaro da Costa. Em Meio à Crise: Souza Dantas e a França Ocupada (1940-1942).

Brasília/Rio de Janeiro, Fundação Alexandre de Gusmão/Centro de História

e Documentação Diplomática, 2008.

GOBINEAU, Arthur de. Essai sur l'inégalité des races humaines. Paris, Firmin-Didot, 1853-1855, 4 v.

HOLANDA, Sérgio Buarque de. Visão do Paraíso. Os Motivos Edênicos do Descobrimento e Colonização do Brasil. Rio de Janeiro, José Olympio, 1959.

KOIFMAN, Fabio. Quixote nas Trevas: o Embaixador Souza Dantas e os Refugiados do Nazismo. Rio de Janeiro, Record, 2002.

MACHADO, Anibal, História da Arte Brasileira. Belo Horizonte, Bibliotheca Mineira de Cultura, 1937.

MEHLSTÄUBLER, Arthur. "August Herborth (1878-1968), a man beyond the limit". Translated by Geert Gabriël Bourgois, Keramos, n. 203/204, January-April 2009, p. 83. MELO, Francisco Homem de; RAMOS, Elaine (orgs.) Linha do Tempo do Design Gráfico no Brasil. São Paulo, Cosac Naify, 2011.

MONTEIRO, Vicente do Rego. Légendes, croyances et talismans des indiens de l'Amazone. Adaptations de P. L. Ducharte. Illustrations de V. do Rego Monteiro. Paris, Éditions Tolmer, 1923.

. Quelques Visages de Paris. Paris, Imprimerie Juan Dura, 1925.

MORAES, Rubens Borba de. Bibliographia Brasiliana. São Paulo, Edusp/Fapesp, 2010.

PASCOAL, Paola da Silva. "Investigação sobre a Constituição de uma 'Cultura Marajoara' nas Artes Visuais e na Arquitetura por Meio do Arquivo de Theodoro Braga", in Anais do XXI Encontro Estadual de História. Campinas, Anpuh, 2012. 
RABELAIS, François. Le quart-livre: texte original et translation en français moderne. Paris, Les Éditions du Seuil, 1997.

RAMOS JR., José de Paula. Leituras de Macunaíma. Primeira Onda (1928-1936). São Paulo, Edusp/Fapesp, 2012.

READERS, Georges (ed.). D. Pedro Il e o Conde de Gobineau. Correspondência Inédita. São Paulo, CEN, 1938.

ROITER, Márcio Alves. "A Influência Marajoara no Art Déco Brasileiro", in Revista UFG, ano XII, n. 8, julho de 2010.

SCHWARTZ, Jorge (org.). Do Amazonas a Paris: As Lendas Indígenas de Vicente do Rego Monteiro. São Paulo, Edusp, 2005.

STADEN, Hans. Warhaftige Historia und beschreibung eyner Landtschafft der Wilden, Nacketen, Grimmigen Menschfresser Leuthen... Marpurg, Andress Kolben, 1557. 